\title{
Fundic Gland Polyposis Associated with Proton-Pump Inhibitor Use
}

\author{
Kenta Hamada, Yoji Takeuchi, Tomofumi Akasaka, Hiroyasu lishi \\ Department of Gastrointestinal Oncology, Osaka Medical Center for Cancer and Cardiovascular Diseases, Osaka, Japan
}

How to cite this article: Hamada K, Takeuchi Y, Akasaka T, lishi H. Fundic gland polyposis associated with proton-pump inhibitor use. EJCRIM 2017;4: doi:10.12890/2017_000607.

Conflicts of Interests: The Authors declare that there are no competing interests.

This article is licensed under a Commons Attribution Non-Commercial 4.0 License

\section{ABSTRACT}

We describe the case of a man with fundic gland polyposis associated with proton-pump inhibitor (PPI) use. Some investigators have reported an association between long-term PPI use and an increase in the risk of developing fundic gland polyps (FGPs). These FGPs are considered to be reversible on stopping PPI treatment. The current patient had used a PPI for 10 years, resulting in multiple FGPs in his gastric body. However, 6 months after cessation of the PPI, the FGPs had obvously regressed, even though a histamine-2 receptor antagonist had subsequently been prescribed. This case demonstrates a link between PPI treatment and FGPs.

\section{LEARNING POINTS}

- Long-term proton-pump inhibitor (PPI) use can increase the risk of developing fundic gland polyps (FGPs).

- This phenomenon is thought to be reversible, and a few case reports have demonstrated spontaneous resolution of FGPs after cessation of PPI use.

- When fundic gland polyposis is detected, a family history of polyposis and a history of PPI use should both be sought.

\section{KEYWORDS}

Fundic gland polyp; gastric polyp; proton-pump inhibitor

\section{CASE DESCRIPTION}

A 57-year-old man without a family history of polyposis presented with an 8-year history of asymptomatic gastric polyps, the number and size of which had been gradually increasing. Serum anti-Helicobacter pylori IgG antibody was negative. He had taken 20 mg of omeprazole every day for 10 years because of gastroesophageal reflux disease (GERD). Oesophagogastroduodenoscopy showed gastric polyps up to 10 $\mathrm{mm}$ in size in the gastric body, with non-atrophic mucosa (Fig. 1). Biopsy specimens revealed fundic gland polyps (FGPs) without dysplasia. Since long-term proton-pump inhibitor (PPI) use can increase FGPs, we therefore considered that his fundic gland polyposis was associated with PPI use. We recommended that he should stop taking omeprazole. Follow-up endoscopy 6 months later showed a dramatic decrease in FGPs (Fig. 2). His GERD symptoms remained well controlled with a histamine-2 receptor antagonist (H2RA) instead of a PPI. 


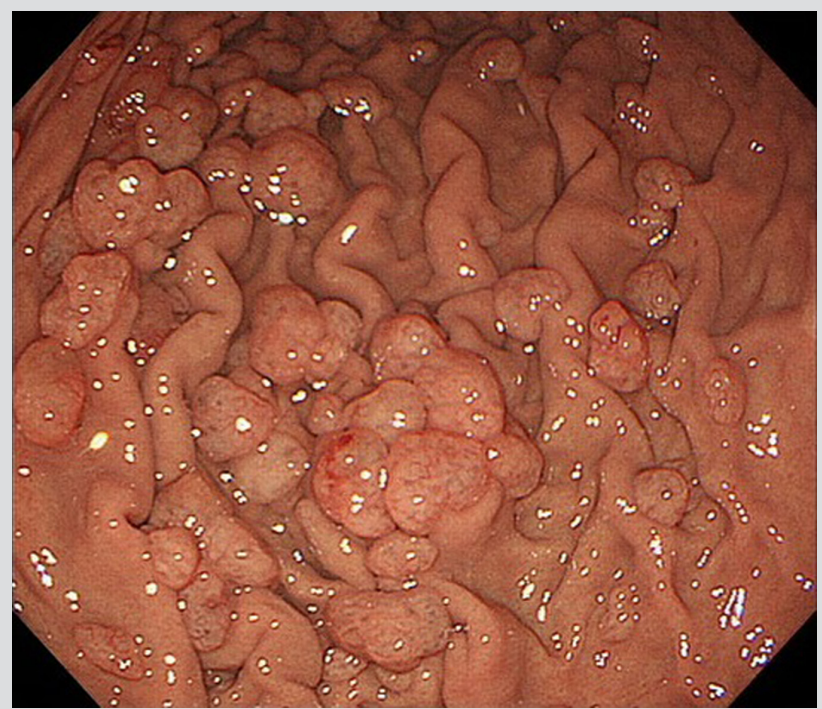

Figure 1. Oesophagogastroduodenoscopy shows gastric polyps of up to $10 \mathrm{~mm}$ in size in the gastric body, with non-atrophic mucosa

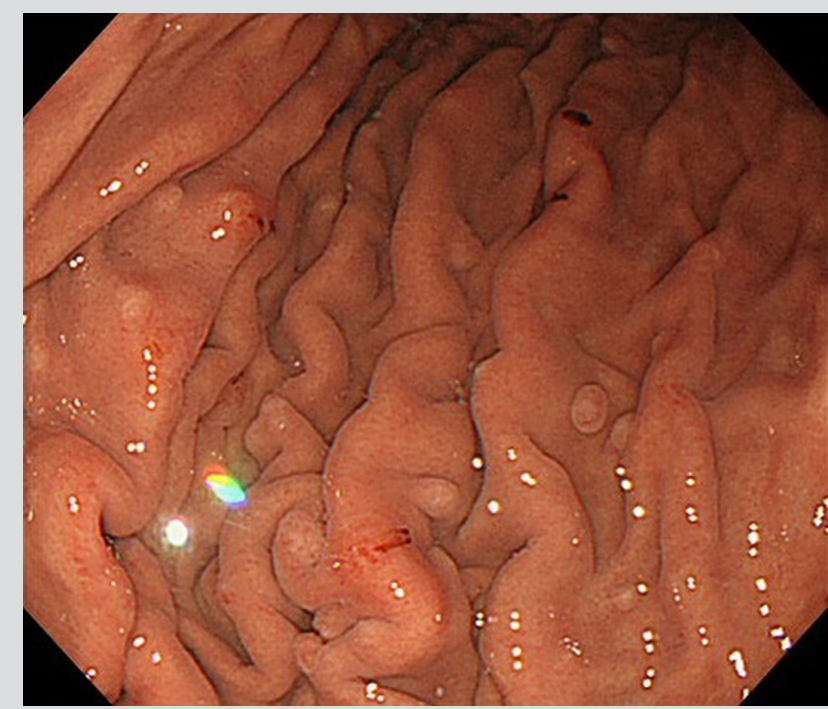

Figure 2. Follow-up endoscopy, 6 months after cessation of proton-pump inhibitor use, shows a decrease in the number and size of the fundic gland polyps

\section{DISCUSSION}

Some investigators have reported an association between long-term PPI use and an increase in FGPs ${ }^{[1-3]}$. It is reported that parietal cell hyperplasia results from acid suppression during PPI use and such hyperplastic parietal cells can be the cause of fundic gland polyposis ${ }^{[3,4]}$. This phenomenon is thought to be reversible, and a few case reports have demonstrated spontaneous resolution of FGPs after cessation of PPI use ${ }^{[2,5]}$. Even though the current patient took H2RA after cessation of PPI, a marked regression in gastric polyposis was observed. This case suggests a direct link between cessation of PPI use and regression of FGPs. When fundic gland polyposis is detected, a family history of polyposis and a history of PPI use should both be sought.

\section{REFERENCES}

1. Graham JR. Gastric polyposis: onset during long-term therapy with omeprazole. Med J Aust 1992;157:287-288.

2. Choudhry U, Boyce HW Jr, Coppola D. Proton pump inhibitor-associated gastric polyps: a retrospective analysis of their frequency, and endoscopic, histologic, and ultrastructural characteristics. Am J Clin Pathol 1998;110:615-621.

3. Jalving M, Koornstra JJ, Wesseling J, Boezen HM, DE Jong S, Kleibeuker JH. Increased risk of fundic gland polyps during long-term proton pump inhibitor therapy. Aliment Pharmacol Ther 2006;24:1341-1348.

4. Cats A, Schenk BE, Bloemena E, Roosedaal R, Lindeman J, Biemond I, et al. Parietal cell protrusions and fundic gland cysts during omeprazole maintenance treatment. Hum Pathol 2000;31:684-690.

5. Kazantsev GB, Schwesinger WH, Heim-Hall J. Spontaneous resolution of multiple fundic gland polyps after cessation of treatment with lansoprazole and Nissen fundoplication: a case report. Gastrointest Endosc 2002;55:600-602. 